Building on the Moon: An Open-Ended Exercise Benchmarking Freshman CMGT Students

Prof. Rebecca N Macdonald, East Carolina University

Dr. Erich Connell, East Carolina University

A registered Architect and Associate Professor of Construction Management. Academic background in the deciplines of; Construction Management, Architecture, and Design. Graduate from Texas A\&M University. 


\title{
Building on the Moon: An Open-Ended Exercise Benchmarking Freshman CMGT Students
}

\begin{abstract}
It has been noted that in the Construction Management degree program students arrive with preconceived notions and experiences about the construction industry. This can lead to established bias that is difficult to identify and address in terms of what student abilities are in relation to the construction management competencies. In an attempt to better understand construction management students' industry perspective/experience, a problem solving exercise, "Building on the Moon" (BOTM), was implemented in the introductory course. BOTM was developed as an opened ended problem statement that would allow the instructors to engage and assess students' experiences as they related to a construction problem. The writing/design exercise followed course textbook reading that provided a pragmatic historical rationale of the evolution of construction process development from its infancy to the current times. The exercise was intended for a group of pairs to propose the construction of a residence on the moon, including a materials list, method of construction, design rationale and a sketch. Fiftyfour students submitted work, with vastly different conclusions. The responses were categorized allowing for quantifiable results. Benchmarking of current students will allow for additional curriculum enrichment and adjustments that take into consideration the extent to which the experience of students meets the needs of educational competencies. The instructors; an architect and an engineer, purposefully provided minimal direction in order to prevent the projection of their professional bias on the students and to gain further insight of students through a less intimidating approach.
\end{abstract}

\section{Introduction}

The perception within the Department of Construction Management at East Carolina University is that students in the undergraduate degree program arrive with preconceived notions and experiences about the construction industry. However, base competencies are quite often not properly understood and frequently misunderstood as only labor and technical based by the students entering the study of Construction Management discipline. ${ }^{2}$ This can lead to predetermined notions that are difficult to identify and therefore address in terms of in the curriculum to establish the competencies within the discipline. ${ }^{3}$ For the fall 2012 semester, the instructors of the introductory course made a major effort to enhance the curriculum and student understanding with a number of engagement activities, one of which was the Building on the Moon exercise.

Open-ended assignments allow students to focus on broad impactful topics through their existing abilities, experiences and new found knowledge to resolve problems. The use of problem solving exercises and a taxonomy of learning can be used to gauge responses. ${ }^{1,5}$ Furthermore the intent is that when students are permitted to self-select and interact in a group they will react in a more positive manner to assignments where they have greater interest, and will think more in 
depth about the issues involved. The authors have attempted to fulfill each of the above suggestions and better understand Construction Management students' industry perspective and base level experience through a problem solving exercise implemented in the introductory course.

\section{Methodology}

Since it is firmly established that open-ended problems are a primary tool to be used in the curriculum and an important way to assess students, the course instructors developed the introductory course assignment, Building on the Moon (BOTM). The selection of the moon as a site was intentional for its unique setting and unchartered territory. With an absence of established structures or any previous student involvement, it provides a baseline for the experience of all students and a blank canvas to see if how their knowledge or experiences transfer to an unfamiliar site. The authors were aware of a similar project that engaged architects and wanted to try a similar problem within their discipline. ${ }^{7}$ BOTM was developed as an opened ended problem statement that would allow the instructors to engage and assess students. The instructions for the assignment are provided in Figure 1. The intention of allowing students to draw upon their construction experiences was for the purpose of engaging them in the learning process as well as their ability to partner with other students.

\section{CMGT 2200 - Assignment 2: BUILDING ON THE MOON}

After reading Chapter 1 and class discussion, you are to partner with a fellow student of either section, to conceptualize the construction of a residential structure on the moon.

Provide a sketch (What are you going to build?), basic material list and possible methods/equipment (How you are going to build it?), and a brief explanation of your selection (Why?).

- 1-2 page submittal to be turned in at the beginning of class on Wednesday, $9 / 5$.

- Use minimum of 10 point font.

- Single or double space.

- Include both of your first and last names on the paper.

- The sketch may be hand drawn and attached.

Figure 1: Assignment Instructions 
This assignment followed course textbook reading which provided a pragmatic historical rationale of the evolution of construction from its origins to the present. ${ }^{5}$ In addition, emphasis was placed upon understanding how residential construction evolved from the primary criteria of survival to that of comfort, and adapted according to location. ${ }^{3}$ Drawing from this insight, the exercise was intended for pairs of students to propose a residence on the moon. This encouraged individual reflection and a team situation requiring students to take their ideas, discuss, and ultimately compromise on a final solution. The submittal was to include a materials list, method of construction, design rationale and a sketch.

Assignments were returned to provide necessary feedback for students to know their grade and areas for improvement. Emphasis was placed on clarity, conciseness, and self-reflection. The following rubric, provided in Table 1, was used for grading.

Table 1: Assignment Rubric

\begin{tabular}{|l|c|c|c|}
\hline Criteria & Lacking & Competent & Proficient \\
\hline Sketch & 0 & 1 & 2 \\
\hline Material List & 0 & 1 & 2 \\
\hline Equipment/Method & 0 & 1 & 2 \\
\hline Explanation & 0 & 1 & 2 \\
\hline Clarity/Professionalism & 0 & 1 & 2 \\
\hline
\end{tabular}

The enrollment for the course was 54 students who were split amongst two sections that met for fifty minutes twice each week. This was assigned at the beginning of the semester and due two weeks later.

\section{Outcome}

The assignment was submitted by 51 of the 54 students with the following scores shown in Table 1. The class average score was nine, with lowest for a single student being 6 and the highest was ten. After discussion, the instructors chose to grade leniently and to encourage students to learn from the exercise with the instructors addressing the issues in the course presentation.

Table 2: Student Scores for the journal critique assignments

\begin{tabular}{|c|c|c|c|c|c|c|}
\hline & BOTM & Sketch & $\begin{array}{c}\text { Material } \\
\text { List }\end{array}$ & $\begin{array}{c}\text { Equipment/ } \\
\text { Method }\end{array}$ & Explanation & $\begin{array}{c}\text { Clarity/ } \\
\text { Professionalism }\end{array}$ \\
\hline Min & 6 & 0 & 1 & 1 & 0 & 1 \\
\hline Max & 10 & 2 & 2 & 2 & 2 & 2 \\
\hline Range & 4 & 2 & 1 & 1 & 2 & 1 \\
\hline Avg & 9 & 1.91 & 1.66 & 1.84 & 1.74 & 1.89 \\
\hline
\end{tabular}

Only 15 assignments submitted during the course met all of the provided guidelines. These assignments were analyzed for thematic trends especially to note pertinent skills of students and how many held them. In regards to the sketch $13.33 \%$ of the students used a CAD based tool, while $46.67 \%$ free-handed and $40 \%$ hand-drafted. Additionally $33.33 \%$ mentioned costs in 
some facet, however this was not addressed in the text or course lectures. The explanations varied greatly, with responses mentioning gravity, labor issues, and smart materials, but did not demonstrate proper relationships.

\section{Conclusion and Suggestions}

The results of the assessment show a majority of students participating in the exercise either disregarded the instructions or did not fully address the requirements. The results also show an awareness of preconceived concepts about construction industry in regards to cost factors and CAD applications. Students focus on labor skills sets and presumptions of their transference to the moon site indicated that their knowledge of core competencies for construction management was deficient. This needs to be addressed in the introductory course and further established through possible linkage to their current understanding. CAD applications and cost factors can be better addressed in courses specific to those topics and students can be made aware to those options for future pursuit.

The style of assignment in this course was a new approach in the curriculum. Students did not expect and are not experienced in this style of assignment within Construction Management education, but this type of assignment is applicable to the industry. The nature of the topics is dynamic and can change with current events and innovations in the construction industry or the world in general. The ambiguities inherent in these exercises require higher level problems solving skills yet often lead to frustration and complaints from students. As an instructor, one should be prepared for the consequences of innovative, open-ended problems versus welldefined, singular solution problems. Continued assessment of students during the fall 2013 semester will provide additional insight in student performance and perception as well as their connection to the profession.

This paper presented the background, methodology, and analysis of the BOTM activity delivered to 54 students. The purpose of the activity was to engage students and gain awareness of their core competencies within the construction management field of study. The activity was built to transfer knowledge from textbook reading to an open ended construction problem statement. This provided a means for instructor to infuse existing curriculum with new content. Possible future works spawned by this assignment include introductory lectures on pertinent topics to further facilitate student learning and advancement for a better recognition to the scope of the discipline.

\section{Bibliographic Information}

1. Decker, T., \& Davidson, K. (2006) Bloom’s and Beyond: Higher Level Questions and Activities for the Creative Classroom.

2. Construction Management Core Competencies: http://cmaanet.org/construction-management-corecompetencies

3. Eisner, E. (2002). Benjamin Bloom:

4. Mulligan, D., \& Knutson, K. (2004) Construction and Culture: A Built Environment.

5. Van Bakel, A. (1995). 'Styles of Architectural Designing' (SAT - Style Assessment Tool) 
6. White, E. (1994) Teaching and Assessing Writing: Recent Advances in Understanding, Evaluating, and Improving Student Performance.

7. 3D Printed Moon Building Designs Revealed. www.bbc.co.uk/news/technology-21293258?print=true 